\title{
Thyroid Screening in Pregnancy: Simple and Reliable ${ }^{1}$ Shamayela Hanif, ${ }^{1}$ Attiqa Amin, ${ }^{1}$ Andleeb Kanwal, ${ }^{2}$ Rizwan Akhter ${ }^{\prime}$ Department of Obstetrics \& Gynecology, Fatima Memorial Hospital, Lahore \\ ${ }^{2}$ Department of Pathology, Fatima Memorial Hospital, Lahore
}

\begin{abstract}
Introduction: Incidence of thyroid disorder affecting pregnancy is 1-3\%. Uncontrolled hypothyroidism or hyperthyroidism is associated with an adverse pregnancy outcome. It results in fetal brain damage and neonatal neuropsychological impairment. Aims \& Objectives: To screen all pregnant women in first trimester for thyroid disease by using TSH in order to prevent morbidity and complications associated with it. Place and duration of study: Department of Obstetrics \& Gynecology, Fatima Memorial Hospital (FMH), Lahore from July 2014-June 2016. Material \& Methods: In our study 703 pregnant women of any gravidity, until 13 weeks of gestation were included. Purposive sampling technique was used to collect data. Mean age was between 17 to 40 years. Women having known thyroid disease, goiter, hyperemesis gravidarum, gestational hypertension, and gestational diabetes mellitus were excluded. TSH (thyroid stimulating hormone) was measured in blood sample, at booking visit in first trimester, by ELISA method (Abbott's "ARCHITECT") in laboratory of FMH. Quantitative value of TSH was considered in three categories like hyperthyroid $(<0.25 \mathrm{uIU} / \mathrm{ml})$, euthyroid $(0.25-2.5 \mathrm{uIU} / \mathrm{ml})$, and hypothyroid $(>2.5 \mathrm{uIU} / \mathrm{ml})$. Mean and standard deviation was used for quantitative variables and clustered bar graphs were used to present the frequency with percentage of each category. ANOVA test was used to check the significance of TSH among three categories. Results: Mean age and TSH levels of hyperthyroid, hypothyroid and euthyroid women were $30.02,29.6,28.87$ years and $0.098,6.275,1.301 \mathrm{uIU} / \mathrm{ml}$ respectively (p-value 0.000).TSH levels significantly differed amongst the three categories of pregnant women, hyperthyroid 47 (6.69\%), hypothyroid 112 (15.93\%) and euthyroid 544 (77.38\%). Conclusion: Our study found TSH to be a simple and reliable test, which can be easily used for screening of thyroid disease in pregnancy to improve fetomaternal outcome.
\end{abstract}

Key words: Thyroid screening, TSH, Pregnancy.

\section{INTRODUCTION}

In ncidence of thyroid disorder effecting pregnancy is $1-3 \%$. Thyroid is an important metabolic hormone. It is not only essential for fetal neural development, when it need thyroid hormone from the mother in early gestation; it is also a requirement for the mother. Uncontrolled hypothyroidism or hyperthyroidism is associated with adverse pregnancy outcome. Thyroid hormone is very important for brain development of fetus and its deficiency can lead to brain damage. ${ }^{1}$

Even subclinical maternal thyroid disease is associated with poor fetal outcome. Subclinical hypothyroidism also effect mother, as can cause preterm delivery, pre-eclampsia and gestational diabetes. Certain risk factors for subclinical hypo and hyperthyroidism are present in pregnant women more than 30 year of age such as diabetes, obesity and hypertension. Connective tissue disorder is also associated with maternal thyroid disease. ${ }^{2}$

It is inexpensive to screen for maternal thyroid disease, as thyroid dysfunction in pregnancy pose risk to mother and fetus. So screening and treatment of women with subclinical hypothyroid disease can result in improvement in maternal and neonatal outcome. $^{3}$

There is debate over screening for thyroid disease in pregnancy but many authorities believe that undiagnosed hypothyroidism is associated with poor obstetric outcome. During pregnancy thyroid functioning usually changes as TSH is decreased in first trimester due to the $\beta$ HCG that stimulates TSH receptor and lead to increased T4, which suppresses TSH. These changes can lead to over- diagnosis of hyperthyroidism and under- diagnosis of hypothyroidism. So it is important to use gestation specific reference range. ${ }^{4}$

Recommendation of thyroid screening in pregnancy is a debatable issue internationally. Either universal 
screening or selective screening should be done. The American College of Obstetrician, American Thyroid Association (ATA) and American Association of Clinical Endocrinologist (AACE) prefer selective rather than universal screening .Some scientific societies as Spanish Society of Endocrinology and Nutrition recommend universal screening. Thyroid screening is important because of the effect of undiagnosed and untreated thyroid disorder on mother and fetus. ${ }^{5,6,7}$

Maternal hypothyroidism, which is diagnosed as low T4 and high TSH, is more common and it's most common cause is iodine deficiency. Regarding cause of hyperthyroidism Graves's disease and transient gestational hyperthyroidism is common. Some women show detectable antiperoxidase and antithyroglobulin antibody and is associated with hyperthyroidism. True gestational hyperthyroidism cannot occur without thyroid receptor antibody (TRAb). ${ }^{8}$

All these types of thyroid disorders effect neonate and is associated with sepsis, transient tachypnoea and respiratory distress. In long term it is associated with congenital hypothyroidism ( $0.8 \%$ in neonates), low neuropsychological development related to intelligence, attention, reading ability, school performance, language and motor performance .9,15 Congenital hypothyroidism has been associated with mother's hypothyroidism and mother's drug intake during pregnancy. ${ }^{15}$

TSH is a very sensitive marker of thyroid dysfunction. ATA (American Thyroid Association) recommend upper normal value should be $2.5 \mathrm{uIU}$ $/ \mathrm{ml}$ in first trimester and $3 \mathrm{uIU} / \mathrm{ml}$ in second and third trimester. If TSH is abnormal than Free T3 and Free T4 is recommended. The purpose of my study is to screen universally in first trimester of pregnancy for hyperthyroid and hypothyroid so as to intervene early in stages of fetal development and prevent irreversible damage in psychomotor development. ${ }^{10}$

As TSH is a simple, reliable, and easily available test. Universal screening is cost effective as the available treatment is economically affordable. Prevalence of thyroid disease in our population is high, thyroid screening should be done antenatally to find out undiagnosed cases so that we can prevent morbidity and complications associated with it. Objective of our study is to screen all pregnant women in first trimester for thyroid disease by using TSH.

\section{MATERIAL AND METHODS}

This cross sectional descriptive study was carried out in outdoor of Obstetrics \& Gynecology Department, Fatima Memorial Hospital (FMH) Lahore. 703 pregnant women were enrolled after taking ethical approval from hospital IRB. Purposive sampling technique was used to collect data. Patient of any gravidity included. Mean age between 17 to 40 years. Those presenting until 13 week since diagnosis of pregnancy were included. Informed consent was obtained from each subject before sample collection. Women having known thyroid disease, goiter and use of medicine effecting thyroid, hyper emesis gravidarum, gestational hypertension, and gestational diabetes mellitus were excluded. Eligible pregnant women were advised TSH when presenting in antenatal clinic. TSH (thyroid stimulating hormone) was measured in blood sample. Patient having abnormal TSH was followed with free T3 and free T4. From July 2014June 2016 data was collected. All data used in the study relate only to single set of result from blood collected in first trimester of pregnancy on their visit to antenatal clinic. All women were included in first trimester.

TSH test was conducted in laboratory of FMH by ELISA method (on Abbott's "ARCHITECT"). Quantitative value of TSH was noted and it was considered into three categories like hyperthyroid $(<0.25 \mathrm{uIU} / \mathrm{ml})$, euthyroid $(0.25-2.5 \mathrm{uIU} / \mathrm{ml})$, and hypothyroid ( $>2.5 \mathrm{uIU} / \mathrm{ml})$.

\section{Statistical analysis:}

All statistical analyses were performed using SPSS software version 21. Mean and standard deviation was used for quantitative variables and clustered bar graphs were used to present the frequency with percentage of each category. ANOVA test was used to check the significance of TSH among three categories.

\section{RESULTS}

Mean and standard deviation of age of patients were 29 years and 4.58. While mean and standard deviation of TSH was $2.01 \mathrm{uIU} / \mathrm{ml}$ and $5.73 \mathrm{uIU}$ $/ \mathrm{ml}$ respectively. The minimum age of patients was 17 years and maximum age was 40 years. On the other hand $0.002 \mathrm{uIU} / \mathrm{ml}$ was minimum TSH value and $100 \mathrm{uIU} / \mathrm{ml}$ was maximum TSH value found in our patients. (Table-1)

Mean age of hyperthyroid, euthyroid and hypothyroid were $30.02,28.87$ and 29.67 years 
whereas mean of TSH category wise were 0.098 , 1.301 and $6.275 \mathrm{uIU} \mathrm{ml}$ respectively. (Table-2)

Overall p-value is 0.000 which clearly demonstrated that TSH value significantly differ among three categories. (Table-3)

$6.69 \%$ (47) patients were found to be hyperthyroid. $15.93 \%$ (112) patients were hypothyroid and $77.38 \%$ (544) patients had normal thyroid function. (Fig-1)

\begin{tabular}{|c|c|c|c|c|}
\hline Characteristics & Minimum & Maximum & Mean & Std. Deviation \\
\hline $\begin{array}{c}\text { Age } \\
\text { xears }\end{array}$ & 17 & 40 & 29.07 & 4.58 \\
\hline $\begin{array}{c}\text { TSH } \\
\text { IIU /ml }\end{array}$ & 0.002 & 100 & 2.01 & 5.73 \\
\hline
\end{tabular}

Table-1: Mean and Standard deviation of Age and TSH

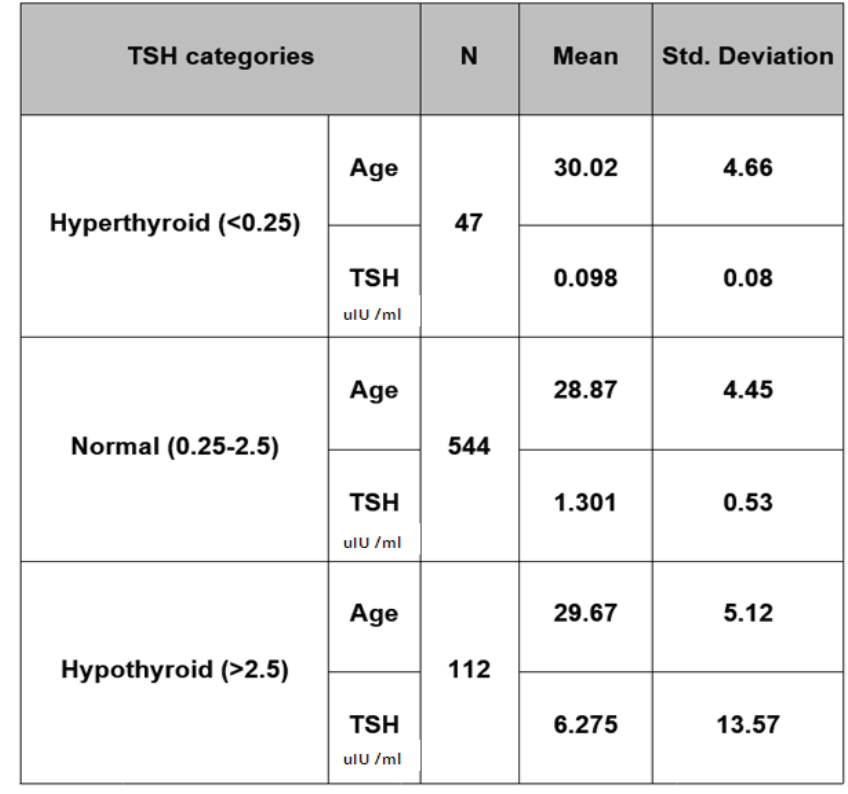

Table-2: Mean and Standard deviation of Age and TSH with respect to $\mathrm{TSH}$ categories

\begin{tabular}{|c|c|c|c|c|c|c|}
\hline \multicolumn{7}{|c|}{ P-Value $($ overall $)=0.000$} \\
\hline \multirow{2}{*}{$\begin{array}{l}\text { (I) TSH } \\
\mathrm{ulU} / \mathrm{ml}\end{array}$} & \multirow{2}{*}{$\begin{array}{l}\text { (J) TSH } \\
\text { ulU /ml }\end{array}$} & \multirow{2}{*}{ Mean Difference (I-J) } & \multirow{2}{*}{ Std. Error } & \multirow{2}{*}{ Sig. } & \multicolumn{2}{|c|}{$95 \%$ Confidence Interval } \\
\hline & & & & & Lower Bound & Upper Bound \\
\hline \multirow{2}{*}{$\begin{array}{l}\text { Hyperthyroid } \\
\qquad(<0.25)\end{array}$} & $\begin{array}{l}\text { Normal } \\
(0.25-2.5)\end{array}$ & -1.204615 & .824591 & .145 & -2.82358 & .41435 \\
\hline & $\begin{array}{c}\text { Hypothyroid } \\
(>2.5)\end{array}$ & -6.178098 & .942614 & .000 & -8.02879 & -4.32741 \\
\hline \multirow{2}{*}{$\begin{array}{l}\text { Normal } \\
(0.25-2.5)\end{array}$} & $\begin{array}{l}\text { Hyperthyroid } \\
(<0.25)\end{array}$ & 1.204615 & .824591 & .145 & -.41435 & 2.82358 \\
\hline & $\begin{array}{l}\text { Hypothyroid } \\
(>2.5)\end{array}$ & $-4.973483^{*}$ & .562778 & .000 & -6.07842 & -3.86855 \\
\hline \multirow{2}{*}{$\begin{array}{l}\text { Hypothyroid } \\
(>2.5)\end{array}$} & $\begin{array}{l}\text { Hyperthyroid } \\
(<0.25)\end{array}$ & $6.178098^{*}$ & .942614 & .000 & 4.32741 & 8.02879 \\
\hline & $\begin{array}{l}\text { Normal } \\
(0.25-2.5)\end{array}$ & $4.973483^{*}$ & .562778 & .000 & 3.86855 & 6.07842 \\
\hline
\end{tabular}

Table-3: Comparisons among TSH categories 


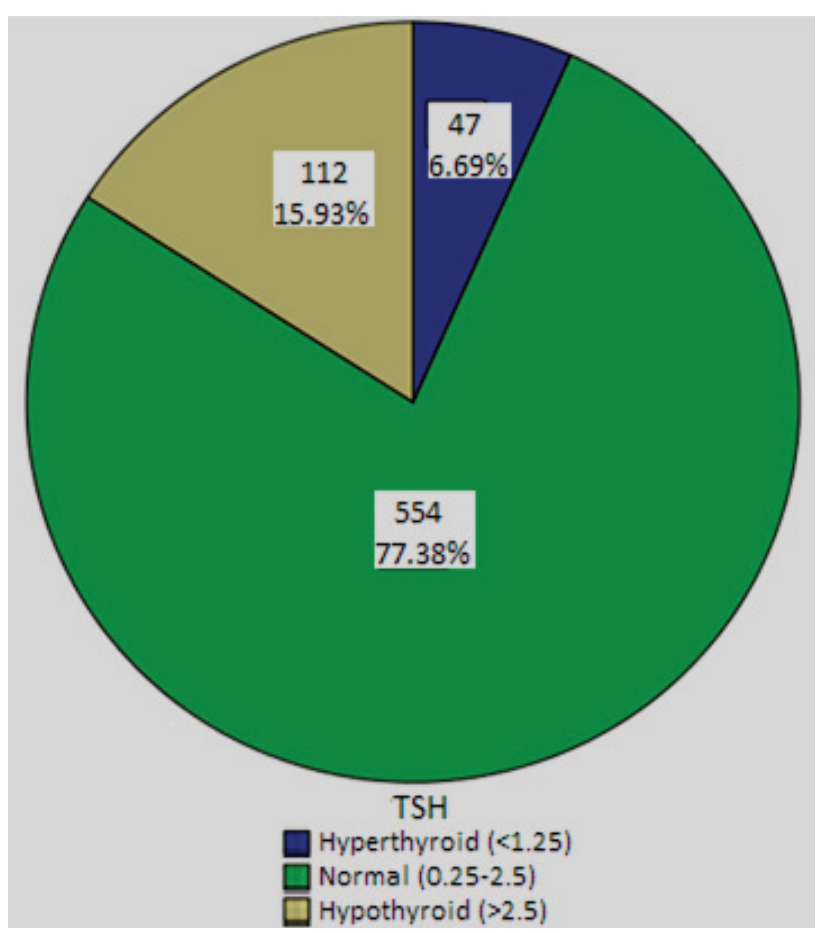

Fig-1: Prevalence of Thyroid Disorder in pregnancy $(\mathrm{N}=703)$

\section{DISCUSSION}

Thyroid disease during pregnancy and its effect on the fetus has been discussed in many clinical guideline as treatment of thyroid disease can improve fetal neurological development. That's why all pregnant patients should be screened for thyroid disease. The test we used for screening was TSH .It is a simple test which is taken in blood sample while performing routine first trimester investigation.

It is very important to use pregnancy specific range. As the prevalence of subclinical hypothyroidism varies between 4 and $17 \%$, it depend on the upper limit of TSH used. ${ }^{11}$

In our study we found that the incidence of hyperthyroidism was $6.6 \%$, patient having normal thyroid screening were $77 \%$ and $15 \%$ of hypothyroidism.

Our findings are comparable to the study carried out by Yassaee $\mathrm{F}$ et al in 2014 at Tehran on 3158 pregnant patients. $21 \%$ of them were diagnosed with hypothyroidism. Subclinical hypothyroidism and overt hypothyroidism were present in 131 (89.1\%) and $16(10.9 \%)$ women respectively. Prevalence of subclinical hypothyroidism was $4.15 \%$. These cases were diagnosed in the first trimester. ${ }^{12}$

Cochrane Database Systematic Reviews. (2015) was carried on 21,846 women. Universal screening was compared with no screening for hypothyroidism before $15+$ weeks of gestation ${ }^{6}$. It showed that incidence of hypothyroid was $5.6 \%$.

Finding in these trial also support that screening diagnose many cases of thyroid abnormality which otherwise would have missed.

These finding are also supported by another study carried out by Sarapatkova H et all on 592 women in the $6^{\text {th }}-10^{\text {th }}$ week of pregnancy who underwent thyropathy screening. This study showed $3.4 \%$ of women with autoimmune throiditis, $1.2 \%$ with subclinical hypothyroidism and 3\% with hypothyroidism for whom no thyropathy risk factor had been evident. Thyropathies were identified in $7.6 \%$ of patients. These findings support the importance of universal screening in pregnancy. ${ }^{14,15}$ There are certain strengths of our study. We utilize TSH as a screening tool which is cheap and convenient. Screening can be done in blood sample taken while performing routine first trimester investigation. Our study presents the costeffectiveness analysis of thyroid screening in women.

The cost-effectiveness of screening and treatment of thyroid disorder might be underestimated in our study, as we have not included some potential benefits (as improvement in maternal and fetal outcome in treated women).

There are many limitation of our study .First the number of pregnant women which were tested was small. If study would have been carried on a large group the result would be more significant. Second, our single-hospital experience may not be generalized to the whole community. As incidence of hypothyroid vary in population due to deficiency of iodine intake. Therefore, it needs further studies including a larger number of pregnant women with testing from several hospitals.

\section{CONCLUSION}

In our setup TSH is a simple and cheap test which can be easily used for screening of thyroid disease in pregnancy. There should be more TSH screening so as to diagnose and treat thyroid dysfunction early leading to better maternal and fetal outcome.

\section{REFERENCES}

1. He Y, He T, Wang y, Xu Z. Comparison of the effect of different diagnostic criteria of subclinical hypothyroidism and positive TPO$\mathrm{Ab}$ on pregnancy outcome. Zhonghua $\mathrm{Fu}$ Chan Ke Za Zhi. 2014 Nov: 49(11): 824-8.

2. Beneventi F, Locatelli E. Alpini C. Associaton between previously unknown connective tissue 
disease and subclinical hypothyroidism diagnosed during first trimester of pregnancy. Fertil Steril. 2015 Nov; 104 (5):1195-201.

3. Jian-xia F, Mi H, Jun T. Referance interval for common thyroid function test, during different stages of pregnancy in Chinese women. Chinese Medical Journal. 2013; 126 (14):2710-2714.

4. Bliddal S, Feldt-Rasmussen U, Boas M, Faber J, Juul A, Larsen T et al. Gestational age-specific reference ranges from different laboratories misclassify pregnant women's thyroid status: comparison of two longitudinal prospective cohort studies. European Journal of Endocrinology. 2014; 170:329-339.

5. Vila L, VelascoI I, Lez SG, Morales F, Sa'nchez E, Torrejo' n SS et al. Controversies in endocrinology on the need for universal thyroid screening in pregnant women. European Journal of Endocrinology. 2014; 170, R17-R30.

6. Stagnaro-Green A, Abalovich M, Alexander E, Azizi F, Mestman J, Negro R et al. Guidelines of the American Thyroid Association for the diagnosis and management of thyroid disease during pregnancy and postpartum. Thyroid 2011;21: 1081-1125.

7. Garber JR, Cobin RH, Gharib H, Hennessey JV, Klein I, Mechanick JI, et all. Clinical practice guidelines for hypothyroidism in adults: cosponsored by the American Association of Clinical Endocrinologists and the American Thyroid Association. Endocrine Practice. 2012; 18: 988-1028.

8. Barbesino G, Tomer Y. Clinical Utility of TSH Receptor Antibodies. J Clin Endocrinol Metab. 2013 Jun; 98(6):2247-2255.

9. Haddow JE, Palomaki GE, Allan WC, Williams JR, Knight GJ, Gagnon J et al. Maternal Thyroid Deficiency during Pregnancy and Subsequent Neuropsychological Development of the Child.N Engl J Med 1999; 341:549-555.

10. http://www.eje-online.org/content/170/1/R17. full

11. Springer D, Jiskra J, Limanova Z. Thyroid in pregnancy: From physiology to screening. Crit Rev Clin Lab Sci. 2017 Mar; 54(2):102-116.

12. Yassaee F, Farahani M, Reza A. Prevalence of Subclinical Hypothyroidism in Pregnant
Women in Tehran-Iran. Int J Fertil Steril. 2014 Jul-Sep; 8(2): 163-166.

13. Spencer L, Bubner T, Bain E, Middleton P. Screening and subsequent management for thyroid dysfunction pre-pregnancy and during pregnancy for improving maternal and infant health. Cochrane Database Syst Rev. 2015 Sep; 21: 9 .

14. Sarapatkova H, Sarapatka J, Frysak Z. What is the benefit of screening for thyroid function in pregnant women in the detection of newly diagnosed thyropathies. Biomed Pap Med Fac Univ Palacky Olomouc Czech Repub. 2013; 157(4):358-362.

15. Anjum A, Afzal M F, Iqbal S M J, Sultan MA, Hanif A. Congenital hypothyroidism in neonates. Indian J Endocrinol Metab. 2014 MarApr; 18(2): 213-216.

\section{The Authors:}

Dr. Shamayela Hanif

Professor,

Department of Obstetrics \& Gynecology,

Fatima Memorial Hospital, Lahore.

Dr. Attiqa Amin

Associate Professor,

Department of Obstetrics \& Gynecology,

Fatima Memorial Hospital, Lahore.

Dr. Andleeb Kanwal

Senior Registrar

Department of Obstetrics \& Gynecology,

Fatima Memorial Hospital, Lahore.

Dr. Rizwan Akhter

Professor,

Department of Pathology,

Fatima Memorial Hospital, Lahore.

\section{Corresponding Author:}

Dr. Attiqa Amin

Associate Professor,

Department of Obs \& Gynae,

Fatima Memorial Hospital, Lahore.

E-mail: attiqachaudhry@hotmail.com 